\title{
"Nos trilhos da memória": construindo uma memória visual dos trabalhadores ferroviários
}

\author{
Elton Luiz Decker* \\ Katia Teixeira Kneipp**
}

Um trem de ferro é uma coisa mecânica, mas atravessou a noite, a madrugada, o dia, atravessou a vida inteira, virou sósentimento. Adélia Prado (Bagagem)

Este artigo pretende relatar brevemente a experiência do Memorial da Justiça do Trabalho no RS, ligado ao Tribunal Regional do Trabalho da $4^{a}$ Região (TRT4), ao entrevistar trabalhadores ferroviários para o vídeo intitulado Nos trilhos da memória (integrante de exposição homônima), realizado em 2009, que trata do papel desta categoria profissional na luta por seus direitos e na consolidação da legislação trabalhista no Brasil.

Em primeiro lugar, situaremos o memorial, seus objetivos, composição e estrutura, e em que condições realiza exposições e vídeos. Num segundo momento, serão explicadas as linhas gerais nas quais se alicerçou o vídeo e a exposição sobre os trabalhadores das ferrovias e sua relação com a justiça e o direito do trabalho. O passo seguinte será refletir sobre como se deu o contato com os ferroviários aposentados e em atividade, suas lideranças sindicais e associativas, e os administradores atuais da Rede Ferroviária Federal; e de

* Servidor público federal, sociólogo e integrante da equipe técnica do Memorial da Justiça do Trabalho no RS.

** Servidora pública federal, bacharel em Direito, pós-graduada em Educação Biocêntrica e integrante da equipe técnica do Memorial da Justiça do Trabalho no RS. 
que forma a cooperação desses atores sociais abriu caminho para a produção do vídeo. Nesse sentido, cabe ressaltar que, de "meros informantes”, eles passaram a ser "corroteiristas" do vídeo e da expografia, pois sua participação trouxe elementos tão novos que alteraram substancialmente o projeto inicial, enriquecendo e valorizando o universo que se quis abordar.

Na década anterior à criação do memorial, a justiça do trabalho e os direitos trabalhistas haviam sido atacados por enunciados contrários à presença estatal na regulação das relações de trabalho. Apesar de termos uma legislação trabalhista das mais avançadas do mundo, conquistada por diversas formas de luta que desembocaram na Constituição de 1988, o período de recessão econômica dos anos de 1990 e a vitória política de forças liberalizantes promoveram a redução do Estado, a abertura econômica ao capital estrangeiro, além de terceirizações, privatizações e flexibilização de direitos sociais. Nesse contexto, inclusive, chegou-se a propor a extinção do judiciário trabalhista.

O Memorial da Justiça do Trabalho no RS foi criado em 2003 por iniciativa da administração do TRT4, com o objetivo de preservar a história do direito e da justiça do trabalho no Rio Grande do Sul, visando a divulgar sua história e seu patrimônio, sobretudo documental, de modo a dar a conhecer sua importância para a constituição da sociedade brasileira. ${ }^{1}$

Numa primeira etapa, o memorial constituiu um pequeno acervo de objetos e realizou entrevistas com alguns juízes e outros operadores do direito. A partir de 2005, a administração do TRT4 nomeou para administrá-lo e dinamizá-lo uma comissão coordenadora composta de magistrados. Também alocou servidores da casa com formação em áreas afins (história, sociologia, ciência política e artes) para constituir sua equipe técnica. Desse momento em diante, o setor passou a recolher e constituir um acervo histórico (processos, documentos administrativos, fotografias, entrevistas e objetos), disponibilizando-o à pesquisa. Ao mesmo tempo, foram realizadas diversas exposições, sempre com a intenção de dar visibilidade ao acervo e buscar sensibilizar o público interno e externo à instituição sobre o valor do patrimônio material e imaterial da justiça do trabalho.

Em síntese, o que se queria era valorizar toda uma trajetória de lutas e conquistas da sociedade brasileira materializada em leis e instituições, a qual, na década anterior, havia sido questionada pelos ventos neoliberais e que, para se sustentar, necessitava do reconhecimento e defesa das instituições que

1 Para mais informações sobre o memorial, ver: http://www.trt4.jus.br/portal/portal/memorial. 
são garantidoras de direitos, por mais que esse papel tutelar das relações de trabalho exercido pelo judiciário trabalhista possa ser tema controverso nos meios políticos e acadêmicos.

De seu início até agora, o memorial percorreu caminhos que o conduziram a aproximar-se da pesquisa acadêmica, defender a preservação documental, articular-se em fóruns e espaços mais amplos visando a concretizar seus objetivos.

É nesse cenário que as exposições produzidas pelo memorial se colocam, na intersecção entre o desejo de reconhecimento (ainda que crítico) do valor e da importância da justiça e do direito do trabalho, nem sempre notados pela sociedade, e o pulsar da vida cotidiana, com sua dinâmica própria, nem sempre percebido ou reconhecido pela instituição em toda a sua pluralidade de matizes.

Nessa perspectiva, trazer à luz da reflexão presente a trajetória dos ferroviários pareceu relevante no sentido de evidenciar a importância dessa categoria para a materialização de direitos depois estendidos a todos os trabalhadores e, simultaneamente, mostrar que mesmo essa trajetória pode ser fortemente abalada quando os interesses econômicos majoritários apontam noutra direção, adquirindo importância, nesses momentos, espaços de reconhecimento de direitos, inclusive do direito à memória.

A importância dos ferroviários para a ampliação de direitos a todos os trabalhadores já está registrada em diversos estudos e foi o mote sobre o qual se organizou o vídeo e a exposição Nos trilhos da memória. A pesquisa bibliográfica nos levou a compreender como esses operários foram precursores e cumpriram papel decisivo na extensão do direito previdenciário aos trabalhadores brasileiros. ${ }^{2}$ Outros estudos analisaram a atividade ferroviá-

2 Nesse sentido, destaca-se a importância da Lei Eloy Chaves, conhecida como a "Lei dos Ferroviários", de 23 de janeiro de 1923, que "previu a criação de uma caixa de aposentadoria e pensões para os empregados de cada uma das empresas de estradas de ferro. Sancionada por Artur Bernardes, foi oriunda de anteprojeto do Departamento Jurídico da Cia. Paulista de Estradas de Ferro e baseou-se em projeto do deputado paulista Eloy Chaves (apresentado em outubro de 1921) [...]. Além da aposentadoria por tempo de serviço, por invalidez, proteção em casos de acidentes de trabalho, auxílio-funeral, entre outros direitos ligados à seguridade social, escreveu a estabilidade no direito brasileiro (decenal, aos ferroviários) e desencadeou movimento de expansão da garantia a outras categorias, o que aconteceu com a Lei 62, de 1935, ampliando-a aos empregados da indústria e comércio. A CLT [aprovada em $1^{\circ}$ de maio de 1943] incorporou a estabilidade, a qual, porém, sofreu duro golpe com a Lei 5.107, que instituiu o FGTS, vigente a partir de janeiro de 1967." (Biavaschi, 2007, p. 203-204). Essa lei é considerada o marco inicial da previdência social no Brasil. 
ria, sua importância para a modernização e desenvolvimento capitalista do país, o papel que desempenhou no processo de urbanização e circulação de mercadorias, e também o seu ocaso, no Brasil, diante da opção - política e econômica - por um novo modelo de circulação de mercadorias focado no transporte rodoviário.

Longe de esgotar o manancial de temas que o estudo dos ferroviários possibilita, foi necessário realizar seleções temáticas e buscar meios para expressar facetas dessa história, feita de conquistas e revezes.

Verificamos que a documentação existente em nosso acervo, em especial os processos trabalhistas, que conta as lutas travadas por estes trabalhadores na esfera judicial, se utilizada isoladamente, não era atrativa o suficiente para sensibilizar e dar a entender a dimensão e o significado da história dessa categoria profissional.

Foi por esse motivo que se optou pela busca de objetos e iconografia relacionados ao universo ferroviário em outras instituições, sobretudo no Museu do Trem da cidade de São Leopoldo (RS), numa parceria que potencializou nosso trabalho, e também com a América Latina Logística, empresa privada que atualmente administra a malha ferroviária do Rio Grande do Sul, a qual nos cedeu trechos de trilhos e dormentes para uma instalação que também compôs a mostra. Decidimos igualmente buscar a cor e o calor dos relatos orais dos próprios ferroviários, que foram veiculados na exposição através de um vídeo.

Para sua elaboração, primeiramente foram realizados contatos com o Sindicato dos Ferroviários do RS, o Centro Cultural Esportivo Ferroviário G. Ferrinho e a Associação dos Ferroviários Aposentados do RS, quando se explicou aos responsáveis por essas entidades o projeto da exposição e do vídeo. Aceito o desafio, tais associações possibilitaram o contato com novas fontes documentais e iconográficas, e nos apresentaram alguns ferroviários que, devido à sua trajetória e interesse em transmitir a memória da atividade ferroviária, possuíam informações, contatos e documentos para auxiliar na elaboração do roteiro do vídeo. Dentre eles, destacamos as informações e documentos obtidos por meio do ferroviário aposentado Julio Enes de Araujo, um "guardião da memória" da categoria e organizador de um vasto acervo sobre a atividade ferroviária.

Com isso, não se quer deixar de observar que existem outros relatos e vivências que seriam provavelmente oferecidas por ferroviários não ligados diretamente às entidades que os representam, e que, nem por isso, devem ser 
desconsiderados. Mas, em razão dos prazos, a metodologia utilizada privilegiou a tomada desses depoimentos agenciados pelas entidades antes referidas, pois, dessa forma, seria muito mais fácil obter uma maior quantidade de entrevistas em um curto espaço de tempo.

O memorial contratou para a execução técnica do vídeo a empresa Estação Elétrica, a qual, ao aceitar o desafio de produzi-lo, envolveu-se profundamente no projeto, superando nossas expectativas, realizando uma verdadeira interlocução, não desprovida de tensões, é verdade, entre o "olhar historiográfico" e o "olhar estético".

Numa visita ao Museu do Trem, o memorial acompanhou uma "roda de memória" que lá se realizava, em que o convidado era o ferroviário aposentado sr. Enio, presidente do Grêmio Esportivo Ferrinho, que registrava seu depoimento. Ali, conhecendo as instalações do museu, que foi uma estação de trem, e ouvindo o relato daquele ferroviário, começou a se delinear o cenário e mesmo alguns elementos ficcionais que poderiam ser utilizados no vídeo.

O passo seguinte foi marcar a tomada de depoimentos no Sindicato dos Ferroviários e na Vila dos Ferroviários, localizada nas proximidades do bairro Humaitá, em Porto Alegre.

A metodologia utilizada para a captação dos relatos que alimentaram o vídeo não foi propriamente a história oral (apesar de ela ter inspirado a nossa perspectiva de trabalho), com toda a sua complexidade teórica, uma vez que a condução das entrevistas foi exercida primeiramente pelo diretor de roteiro e de cena da produtora contratada, Alexandre Derlan. Este, apesar de seguir as linhas gerais do roteiro a ele encaminhado previamente e franquear parte da condução das entrevistas ao memorial, serviu-se, primordialmente, de técnicas de entrevista próprias de sua experiência profissional na área de cinema e publicidade, procurando otimizar o tempo, priorizando a qualidade da captação de imagens e a busca de conteúdos mais impactantes, curiosos e emocionalmente densos.

Cumpre destacar que a quantidade de ferroviários que compareceu espontaneamente ao sindicato na data combinada para oferecer seu relato acerca de sua trajetória profissional e vivências quotidianas foi algo surpreendente, demonstrando, de um lado, que, numa sociedade marcada pela imagem, a ideia de produção de um vídeo é, muitas vezes, bem mais atrativa e mobilizadora das vontades do que a de tomada de entrevistas para fins acadêmicos, pois o retorno da participação no primeiro veículo é certamente mais mensurável e acessível a esse grupo social; e, de outro, o desejo desses 
atores sociais de legarem à posteridade, na forma de imagens em movimento, memórias de sua categoria profissional, antes tão significativa e com papel protagônico na história brasileira, hoje tão reduzida e esquecida.

Assim, certas questões metodológicas - por exemplo, buscar condições para deixar os entrevistados em situação confortável e promover uma entrevista que gradativamente parta de questões mais genéricas e vá se aprofundando - tiveram que ser deixadas de lado, com o fito de contemplar a expectativa de que todos fossem ouvidos e pudessem expressar opinião em um vídeo que, afinal de contas, tratava de algo que lhes era familiar. O que se percebeu nos relatos obtidos no sindicato e na Vila dos Ferroviários foram representações muito significativas do universo da categoria, da forma de pensar desses trabalhadores, dos seus hábitos, costumes, lutas, derrotas e conquistas, mostrando uma certa continuidade de traços de uma identidade que, mesmo diante dos momentos mais difíceis, permanece alicerçada no trabalho como elemento de reconhecimento e de conexão com a vida social.

As diferenças entre a metodologia da história oral para fins de conhecimento dos fenômenos sociais e as técnicas da área cinematográfica ficaram explicitadas, por exemplo, quando se solicitou que um dos ferroviários aposentados, reconhecido pelos demais como informante privilegiado, dada a sua longa trajetória na defesa da sua categoria e seu interesse particular em preservar documentos sobre a história desses trabalhadores, fosse ouvido em estúdio, juntamente com um representante da administração da Rede Ferroviária Federal (RFFSA). Enquanto o relato do engenheiro da empresa, certamente mais acostumado com a tecnologia dos meios de comunicação, fluiu com grande profusão de detalhes, a entrevista com o ferroviário aposentado foi marcada por momentos de tensão, pois, fora de um ambiente que lhe era familiar, ele ficou bloqueado para fornecer as informações sobre o período em que fora perseguido pelo regime militar. Já sem paciência para dar continuidade à entrevista, saiu de cena o diretor do vídeo, habituado ao timing do cinema e da publicidade, e a entrevista passou a ser conduzida por um integrante da equipe técnica do memorial. O relato sobre o que aquele operário havia passado no período ditatorial não ficou gravado em seus detalhes no estúdio, mas sim confidenciado aos pesquisadores no caminho de volta para sua casa, no município de Canoas.

Essas diferenças entre as metodologias da história, da sociologia, da comunicação social e do cinema não invalidam, obviamente, o resultado do trabalho realizado, que foi a produção de um vídeo misto de ficção e 
documentário, o qual pretende comunicar, ao mesmo tempo, uma narrativa histórica baseada em fatos, documentos, relatos e vivências, e uma narrativa ficcional, calcada na dramaturgia e em um narrador-condutor fictício, de forma a tornar a mensagem mais atrativa.

No lançamento da exposição Nos trilhos da memória, ocorreu uma verdadeira "invasão" dos ferroviários ao saguão do prédio do TRT4 para assistir, em primeira mão, ao vídeo e, após, realizaram-se diversas exibições seguidas de debate no próprio sindicato, no Clube Ferrinho, no Museu de Comunicação Social Hipólito da Costa e no Museu do Trem, dentre outros espaços. O sucesso do empreendimento se deveu, sem dúvida, à participação direta dos ferroviários, que reconheceram sua história e suas vivências apresentadas/ representadas nas imagens em movimento do vídeo documentário/ficcional. Talvez seja essa capacidade de identificação a maior qualidade do material.

Na continuidade do projeto "Nos trilhos da memória” e diante da repercussão de tal iniciativa na categoria dos ferroviários, foram realizadas várias outras entrevistas com esses trabalhadores, que denominamos de "rodas de memória”, uma dos quais na cidade de Rio Grande (RS), em 2010, conduzida pela equipe do memorial, em que foi, dessa vez, utilizada a metodologia própria da história oral e cujos resultados fazem parte do nosso acervo. Também ocorreu a veiculação do vídeo na TV Justiça e na web, podendo o mesmo ser acessado nos links a seguir:

Nos trilhos da memória - parte 1

http://www.youtube.com/watch?v=YJmBMF6r7JE

Nos trilhos da memória - parte 2

http://www.youtube.com/watch?v=tbDkqol6Ja8

Dessa forma, mesmo com algumas dificuldades metodológicas presentes no âmbito do trabalho multidisciplinar, que devem ser reconhecidas e contornadas, a utilização de um vídeo documentário como elemento motivador da realização de entrevistas mostrou-se uma estratégia interessante a ser considerada quando se busca investigar o universo de representaçóes de um determinado grupo social, principalmente quando se consegue o contato com entidades que abrem espaço para sua realização. $\mathrm{O}$ vídeo, enfim, pode ser um instrumento poderoso para dar visibilidade às representações produzidas por uma determinada categoria profissional. De outro lado, as entrevistas 
completas devem ser mantidas nos acervos para que, caso algum pesquisador tenha interesse em aprofundar a análise dos depoimentos, se possa fornecer mais elementos ao aprofundamento da pesquisa.

\section{Referência}

BIAVASCHI, M. B. O Direito do Trabalho no Brasil - 1930-1942: a construção do sujeito de direitos trabalhistas. São Paulo: LTR, 2007.

Resumo: o artigo relata a experiência de tomada de depoimentos para a elaboração do vídeo Nos trilhos da memória, bem como situa o lugar institucional onde ele foi realizado.

Palavras-chave: vídeo, trabalhadores ferroviários, conquista de direitos.

"In the tracks of memory": building a visual memory of railway workers

Abstract: The article reports the experience of taking the statements to prepare the video In the tracks of memory. It also situates the institutional place where it was made.

Keywords: video, railway workers, achievement of rights.

Recebido em 10/03/2012

Aprovado em 06/04/2012 